\title{
Hypermetabolism Following Moderate to Severe Traumatic Acute Brain Injury: A Systematic Review
}

\author{
Norine Foley, ${ }^{1}$ Shawn Marshall, ${ }^{2}$ Jill Pikul, ${ }^{3}$ Katherine Salter, ${ }^{1}$ and Robert Teasell ${ }^{4}$
}

\begin{abstract}
Elevations of metabolic rate following traumatic brain injury (TBI) have been reported previously, with estimates ranging from $32 \%$ to $200 \%$ above normal values. The aim of this systematic review was to describe the pattern of energy expenditure during the first 30 days following TBI. We searched six databases for trials that measured the energy expenditure at least once during the first 30 days post-injury and compared that value to one that would be predicted in the non-injured state. We identified 24 studies, three of which were randomized controlled trials (RCTs). The sample sizes of the included studies ranged from 6 to 80 (mean, 24.7), and the mean Glasgow Coma Scale (GCS) score of subjects was 4.8. Mean energy expenditure, expressed as a percentage of a predicted value, ranged from $75 \%$ to $200 \%$. The lowest values were reported in patients admitted in brain death. Several factors were found to have modulating effects on energy expenditure. The administration of paralyzing agents, sedatives, or barbiturates reduced metabolic rate by approximately $12-32 \%$. Propranolol and morphine were associated with smaller decreases in energy expenditure. Factors that do not appear to augment the hypermetabolic response included the administration of steroids and method of feeding (enteral vs. parenteral). Based on our results, it was unclear if elevated temperature, the presence of extracranial injury, or the severity of injury further exacerbate hypermetabolism. We conclude that energy expenditure following TBI is highly variable, and the use of standard factors to estimate the energy needs of individual patients are inappropriate and should be discouraged.
\end{abstract}

Key words: energy expenditure; head injury; nutrition; review

\section{Introduction}

$\mathbf{T}$ He HYPERMETABOlic STATE that accompanies traumatic brain injury (TBI) has been well documented (Loan, 1999; Long et al., 1979; Ott et al., 1989; Pepe and Barba, 1999; Roberts, 1995; Wilson and Tyburski, 1998; Yanagawa et al., 2002). Although our understanding of the etiology of this phenomenon is not complete, the release of various cytokines and counter-regulatory hormones, mediated through the acute phase response, is believed to be contributory (Chiolero et al., 1989a; Young et al., 1988, 1992). Wide variations in both the magnitude and time course of metabolic perturbations have been reported, with energy expenditures ranging from $32 \%$ (Long et al., 1979) to $200 \%$ (Haider et al., 1975) above that which would be predicted in the non-injured state. The length of time that metabolic rate remains elevated following head injury is also uncertain. Work by Long et al. (1979) suggested that hypermetabolism resolves within the first 20 days, while other investigators have reported elevations in metabolic rate that have persisted at 1 year following head injury (Haider et al., 1975).

The present state of uncertainty regarding both the extent and duration of hypermetabolism following head injury limits clinicians' ability to effectively guide nutritional interventions. The task of estimating caloric requirement may be less problematic in the early stages of recovery, where indirect calorimetry is often easily and routinely performed. However, in some circumstances, such as in the absence of this technology, estimating energy expenditure becomes more difficult. Increased mortality, infections, and complications have been associated with caloric deficit (Rapp et al., 1983; Villet et al., 2005), while feeding in excess of requirement may lead to hepatic steatosis and difficulty weaning from mechanical ventilation (Wilson and Tyburski, 1998). Since negative outcomes have been associated with both under- and overfeeding, it is important to estimate caloric requirement thoughtfully.

\footnotetext{
${ }^{1}$ Aging, Rehabilitation \& Geriatric Care Program, Lawson Health Research Institute, Parkwood Hospital, London, Ontario, Canada.

${ }^{2}$ Department of Medicine, University of Ottawa, The Ottawa Hospital Rehabilitation Centre, Ottawa, Ontario, Canada.

${ }^{3}$ Critical Care, Trauma and Transplant Program, London Health Sciences Centre, University Campus, London, Ontario, Canada.

${ }^{4}$ Department of Physical Medicine and Rehabilitation, Parkwood Hospital, London, Ontario, Canada.
} 
In 2000, citing insufficient data upon which to base standards regarding the nutritional care of patients with severe brain injury, the Brain Trauma Foundation, the American Association of Neurological Surgeons, and the Joint Section on Neurotrauma and Critical Care (2000) collectively released guidelines recommending that $140 \%$ and $100 \%$ of resting metabolic expenditure be replaced in nonparalyzed and paralyzed patients, respectively; these guidelines were recently revised (2007b). Although the recommendations for caloric replacement remain unchanged (100-140\%), a distinction is no longer made between these two groups of patients, since energy expenditures are now thought to be $20-30 \%$ above pre-injury values, even with paralysis. We sought to define energy expenditure more precisely, by considering the contribution of additional factors. Therefore, the aim of this systematic review was to (i) describe the pattern of energy expenditure during the first 30 days following TBI and (ii) examine the effects of possible mediating factors such as the use of commonly used medications, the presence of extracranial injury, elevated temperature, method of feeding, and severity of injury, in order to support a more informed process of clinical decision-making.

\section{Methods}

\section{Search strategy and selection criteria}

A systematic review of the literature was conducted to identify all studies measuring energy expenditure within the first month following acute TBI. Six electronic databases were searched: Cumulative Index to Nursing and Allied Health Literature (Cinahl), Medline, Embase, ISI Web of Science, and Cochrane Library. Search dates depended on the database, but ranged from 1966 to December 2007. Search terms varied slightly across databases and are presented in Table 1. Selecting suitable search terms was challenging given that hypermetabolism and energy expenditure are not indexed terms in any of the databases. The reference lists of all potentially included articles, as well as those from review papers, were hand searched for studies not identified through the original literature search.

The titles and abstracts of each of the citations retrieved through the search process were reviewed independently for potential inclusion by two investigators (N.F. and K.S.). The original articles were retrieved if (a) it was unclear if the subjects had suffered from acute brain injury or (b) energy expenditure had been measured based on the information provided in the abstract. Consensus following discussion was used to resolve conflicts over eligibility of identified articles. Following the initial selection process, all studies found to be potentially suitable were reviewed and assessed for final inclusion.

\section{Inclusions and exclusions}

This review was restricted to original research articles, written in the English language, published in peer-reviewed

Table 1. Literature Search Results

\begin{tabular}{|c|c|c|c|c|c|c|c|c|c|}
\hline \multirow[b]{2}{*}{ Database } & \multirow[b]{2}{*}{ Search terms } & \multirow[b]{2}{*}{ Hits } & \multicolumn{6}{|c|}{ Exclusions } & \multirow[b]{2}{*}{$\begin{array}{l}\text { Potential } \\
\text { inclusions }\end{array}$} \\
\hline & & & Duplicates & $\begin{array}{l}\text { Not } \\
\text { TBI }\end{array}$ & $\begin{array}{l}\text { EE not } \\
\text { measured }\end{array}$ & Non-human & Non-English & $\begin{array}{l}\text { Review/ } \\
\text { opinion }\end{array}$ & \\
\hline MEDLINE & $\begin{array}{l}\text { Brain injuries [Mesh] } \\
\text { Craniocerebral } \\
\text { trauma [Mesh] } \\
\text { Hypermetabolic/ } \\
\text { hypercatabolic } \\
\text { Protein-energy } \\
\text { malnutrition [Mesh] } \\
\text { Metabolism [Mesh] }\end{array}$ & 130 & - & 44 & 28 & 9 & 11 & 10 & 28 \\
\hline EMBASE & $\begin{array}{l}\text { Brain injury } \\
\text { Diet therapy }\end{array}$ & 72 & 6 & 26 & 31 & 1 & 3 & 2 & 3 \\
\hline $\begin{array}{l}\text { ISI Web of } \\
\text { Science }\end{array}$ & $\begin{array}{l}\text { Brain injury } \\
\text { Hypermetabolism }\end{array}$ & 37 & 3 & 2 & 5 & 24 & 0 & 3 & 0 \\
\hline CINAHL & $\begin{array}{l}\text { Brain injury } \\
\text { Hypermetabolism } \\
\text { Energy metabolism }\end{array}$ & 6 & 5 & 0 & 1 & 0 & 0 & 0 & 0 \\
\hline $\begin{array}{l}\text { EBM } \\
\text { Reviews }\end{array}$ & $\begin{array}{l}\text { Brain injury } \\
\text { Energy metabolism } \\
\text { Metabolism } \\
\text { Hypermetabolism }\end{array}$ & 5 & 3 & 0 & 1 & 0 & 0 & 1 & 0 \\
\hline Psycinfo & $\begin{array}{l}\text { Traumatic brain injury } \\
\text { Head injury } \\
\text { Metabolism } \\
\text { Brain metabolism } \\
\text { Hypermetabolism }\end{array}$ & 2 & 0 & 0 & 1 & 1 & 0 & 0 & 0 \\
\hline Total & & 252 & 17 & 73 & 67 & 35 & 14 & 16 & 31 \\
\hline
\end{tabular}

EE, energy expenditure; TBI, traumatic brain injury. 
journals conducting subject-level investigations. Included trials were limited to those in which either all, or an identified subgroup of the subjects, had suffered from acute (injury occurring within 2 weeks) traumatic, moderate to severe brain injury, as defined by the study's authors. Trials that recruited subjects with or without extracranial injuries were included. To be eligible for inclusion, subject energy expenditure had to be measured at least once within the first 30 days of injury, and the value expressed as a percentage of predicted energy expenditure (PEE). The latter requirement was included to enable comparability among trials. Trials which did not present summary statistics of the outcomes of interest were still included if sufficient patient level data were available, either in text or figure format to enable a reasonable estimation or calculation of energy expenditure. Studies that included subjects who were less than 18 years of age were also included, provided this group did not comprise more than $50 \%$ of the total sample. There were no restrictions based on study design.

Non-English language studies, reviews, letters to the editor, commentaries, and other non-investigational publications were excluded. Abstracts were excluded because of lack of reporting detail. Trials in which the sample was composed entirely of subjects recovering from non-traumatic intracerebral haemorrhages were also excluded. Studies with sample sizes of less than three were excluded.

\section{Data abstraction}

One investigator (N.F.) abstracted the following information, which was verified for accuracy by a second investigator (K.S.): sample size, patient characteristics, details of medical/surgical/feeding management, time (hours/ days) when energy expenditure assessments were obtained, details of indirect calorimetry measurements, the method that was used to predict estimates of subjects' energy expenditure, the presence of fever or infections, and whether subjects were in a fed or unfed state at the time metabolic measurements were performed. The type of energy expenditure that was measured was also noted. Resting energy expenditure (REE) is a term used to describe the number of calories required to sustain all metabolic processes in an inactive, post-prandial, thermo-neutral state during a 24-h period. Additional energy requirements associated with absorption and digestion are estimated to be approximately $10 \%$ of total energy expenditure (Elwyn, 1980). Basal energy expenditure (BEE) differs from REE only in that it does not include the metabolic demands of absorption and digestion.

Due to the heterogeneity of methods and outcomes recorded, pooled analyses were not possible. Consequently, results are reported descriptively. Means \pm standard deviations are reported. Measured energy expenditure (MEE) was expressed as a percentage of the predicted energy expenditure (MEE/PEE $\times 100 \%)$. Values which fell outside of the range of normal (90-110\%) (Long et al., 1979) were assumed to be the result of injury. Subjects with values greater than $110 \%$ and less than $90 \%$ were considered to be hypermetabolic and hypometabolic, respectively. We accepted the authors' choice of method to estimate PEE, which is typically calculated using models that include variables such as sex, height, weight, and age.

\section{Results}

The formal search strategy yielded 252 hits. Following the initial review process, 221 articles were excluded leaving 31 articles for possible inclusion. Reasons for initial exclusions are presented in Table 1. From hand searching, an additional 25 potentially eligible articles were identified. From this pool of 56 articles, 32 were excluded (Table 2). Following final review, 24 articles remained which comprised the final sample (Bitzani et al., 1999; Borzotta et al., 1994; Bruder et al., 1991, 1994, 1998; Chiolero et al., 1989b; Clifton et al., 1984, 1986; Dempsey et al., 1985; Dickerson et al., 1990; Esper et al., 2006; Hadfield et al., 1992; Haider et al., 1975; Kolpek et al., 1989; McCall et al., 2003; Moore et al., 1989; Ott et al., 1994; Petersen et al., 1993; Raurich and Ibanez, 1994; Robertson et al., 1984, 1985; Weekes and Elia, 1996; Young et al., 1985, 1996).

\section{Study characteristics}

Mean sample size of all included studies was $24.7 \pm 21.5$ subjects (range, 6-80). Four trials included a percentage of subjects [50\% (Hadfield et al., 1992; Kolpek et al., 1989; Petersen et al., 1993) and 70\% (Esper et al., 2006)] who had not suffered from TBI, although data for these subjects were presented separately. Details of the inclusion/exclusion criteria were provided in six of the trials (Borzotta et al., 1994; Bruder et al., 1998; Chiolero et al., 1989b; Esper et al., 2006; McCall et al., 2003; Moore et al., 1989). The characteristics of a cohort of patients, recruited conveniently or consecutively, without establishing eligibility criteria, were described in the remainder of trials. There were four randomized controlled trials (RCTs) (Borzotta et al., 1994; Young et al., 1985, 1996) or quasi-randomized controlled trials (Robertson et al., 1985) evaluating routes of feeding (parenteral versus enteral) and zinc administration. One single group intervention study assessed the effect of propranolol as an intervention unrelated to usual care (Chiolero et al., 1989b). The remaining trials measured the energy expenditure of patients during the natural course of their recovery, subject to medical practices that were common at the time of publication. Three studies included data that was collected retrospectively (Esper et al., 2006; Hadfield et al., 1992; Moore et al., 1989).

\section{Patient characteristics}

The mean ages of patients enrolled in all studies ranged from 21 (Bruder et al., 1991; Moore et al., 1989) to 47 (Bitzani et al., 1999) years. Eight trials included a proportion of subjects (up to $40 \%$ ) who were less than 18 years (Clifton et al., 1984, 1986; Dempsey et al., 1985; Dickerson et al., 1990; Haider et al., 1975; Moore et al., 1989; Robertson et al., 1984). Generally, gender ratios were unequal, such that a greater proportion of males were enrolled.

Subjects in the majority of trials suffered from acute TBI due to motor vehicle accidents, falls and gunshot wounds. A portion of the subjects included in five trials suffered brain injuries that may have not been traumatic in nature, including intracerebral hematomas, diffuse brain injury, or cerebral thrombosis (Clifton et al., 1984, 1986; Haider et al., 1975; Robertson et al., 1984, 1985). Mean Glasgow Coma Scale (GCS) scores ranged from 4.8 (Dickerson et al., 1990) to 9 (Petersen et al., 1993) among the 18 trials where the value was reported or could be calculated. In four cases where a mean 
Table 2. Details of Exclusions from Formal Literature and Manual Searching

\begin{tabular}{|c|c|c|}
\hline Exclusions & $\begin{array}{l}\text { Studies identified through } \\
\text { literature search }(\mathrm{n}=31)\end{array}$ & $\begin{array}{l}\text { Studies identified through } \\
\text { hand searching }(\mathrm{n}=25)\end{array}$ \\
\hline $\begin{array}{l}\text { Energy expenditure not } \\
\text { measured }\end{array}$ & $\begin{array}{c}7 \\
\text { (Clifton et al., 1981; Dahlberg et al., 1985; } \\
\text { Fell et al., 1984; Godbole et al., 1991; } \\
\text { Kaufman et al., 1987; Nataloni et al., 1999; } \\
\text { Stechmiller et al., 1994) }\end{array}$ & $\begin{array}{l}\text { (Bivins et al., 1986; } \\
\text { Chiolero et al., 1989a; } \\
\text { Fife and Jagger, 1984) }\end{array}$ \\
\hline $\begin{array}{l}\text { Energy expenditure not } \\
\text { compared with a } \\
\text { predicted value }\end{array}$ & $\begin{array}{l}6 \\
\text { (Bucci et al., 1988; Deutschman et al., 1986; } \\
\text { Feldman et al., 1993; Hatton et al., 1997; } \\
\text { Hatton et al., 2006; Krakau et al., 2007) }\end{array}$ & $\begin{array}{c}3 \\
\text { (Ott et al., 1999; } \\
\text { Suchner et al., 1996; } \\
\text { Waters et al., 1986) }\end{array}$ \\
\hline $\begin{array}{l}\text { Energy expenditure measured } \\
>30 \text { days after injury } \\
>50 \% \text { of subjects }<18 \text { years }\end{array}$ & $\begin{array}{c}1 \\
(\text { Denes, 2004) } \\
1 \\
(\text { Lazarov, 1999) }\end{array}$ & $\begin{array}{c}1 \\
\text { (Aquilani et al., 2000) } \\
0\end{array}$ \\
\hline Review, commentary, or other & $\begin{array}{c}4 \\
\text { (Anderson, 1987; Cruz, 1997; } \\
\text { Hadley, 1989; Robertson, 1991) }\end{array}$ & $\begin{array}{c}1 \\
\text { (Gadisseux et al., 1984) }\end{array}$ \\
\hline $\begin{array}{l}\text { Subject-level data presented in } \\
\text { graphical form-individual } \\
\text { data points undecipherable }\end{array}$ & (Sunderland and Heilbrun, 1992) & 0 \\
\hline Duplication & Presented in Table 1 & $\begin{array}{l}2 \\
\text { (Fried et al., 1989; } \\
\text { Hadfield and Little, 1992) }\end{array}$ \\
\hline $\begin{array}{l}90 \% \text { of subjects suffered } \\
\text { from mild TBI }\end{array}$ & 0 & $\begin{array}{c}1 \\
\text { (Piek et al., 1989) }\end{array}$ \\
\hline Insufficient reporting detail & 0 & $\begin{array}{c}1 \\
\text { (Long et al., 1979) }\end{array}$ \\
\hline Total number of excluded studies & $\begin{array}{l}20 \\
11\end{array}$ & $\begin{array}{l}12 \\
\mathbf{1 3}\end{array}$ \\
\hline Total studies remaining & 24 & \\
\hline
\end{tabular}

GCS score was not provided, scores ranged from 3 to 8 (Bitzani et al., 1999; Clifton et al., 1986), 4 to 7 (Robertson et al., 1984), or were all below 7 (Robertson et al., 1985). The authors of one trial (Hadfield et al., 1992) reported that the Abbreviated Injury Scores for the head and neck were all either 4 or 5, indicating severe to critical injury (Baker et al., 1974). Haider et al. (1975) did not use a scale to assess the severity of head injury, although they described the subjects as having suffered from "severe brain damage." The percentage of patients within individual trials suffering from extracranial injuries ranged from $21 \%$ (Clifton et al., 1984) to $100 \%$ (Petersen et al., 1993). Only one study included subjects suffering exclusively from isolated head injury (Bitzani et al., 1999). It was unclear whether subjects with extracranial injuries had been included in six trials (Clifton et al., 1986; Esper et al., 2006; Haider et al., 1975; Kolpek et al., 1989; Robertson et al., 1984, 1985).

Three publications recruited subjects from the same institution during overlapping recruitment periods (Clifton et al., 1984, 1986; Robertson et al., 1984); therefore, it is likely that there is some duplication of results.

\section{Patient management}

Patients were all managed according to established institutional protocols or at the discretion of the attending physicians. Routine care often included measures to prevent intracranial hypertension (controlled hyperventilation, sedation, barbiturates, analgesics, muscle relaxation, paralyzing agents, salt and water restrictions, or diuretics (Table 3). Details regarding routine management, with emphasis on medications that could alter metabolic rate, were often lacking, or it was unclear what individual patients had received. The authors of one trial stated that subjects did not receive any medications known to alter metabolic rate (Kolpek et al., 1989). A portion of the subjects, ranging from $33 \%$ to $100 \%$, reported from 10 studies underwent either craniotomy or surgical debridement (Table 3). No details of surgical procedures were provided in the remaining studies. All subjects in all trials were mechanically ventilated upon admission to hospital.

\section{Metabolic measurements}

Indirect calorimetry was performed using a portable metabolic cart in all but six studies (Clifton et al., 1984; Dempsey et al., 1985; Haider et al., 1975; Raurich and Ibanez, 1994; Robertson et al., 1984), most of which were published before this technology became commercially available (around 1984). In the remainder of studies, other analytical techniques were used to collect and measure oxygen consumption and carbon dioxide production. In one study, a portion of the metabolic measurements were obtained using a metabolic cart, which became available during the study's duration (Robertson et al., 1984). Among the studies that used a metabolic cart, the sampling period varied from less than $30 \mathrm{~min}$ (Esper et al., 2006; Hadfield et al., 1992; Kolpek et al., 1989; Moore et al., 1989; Petersen et al., 1993; Young et al., 1985), to 


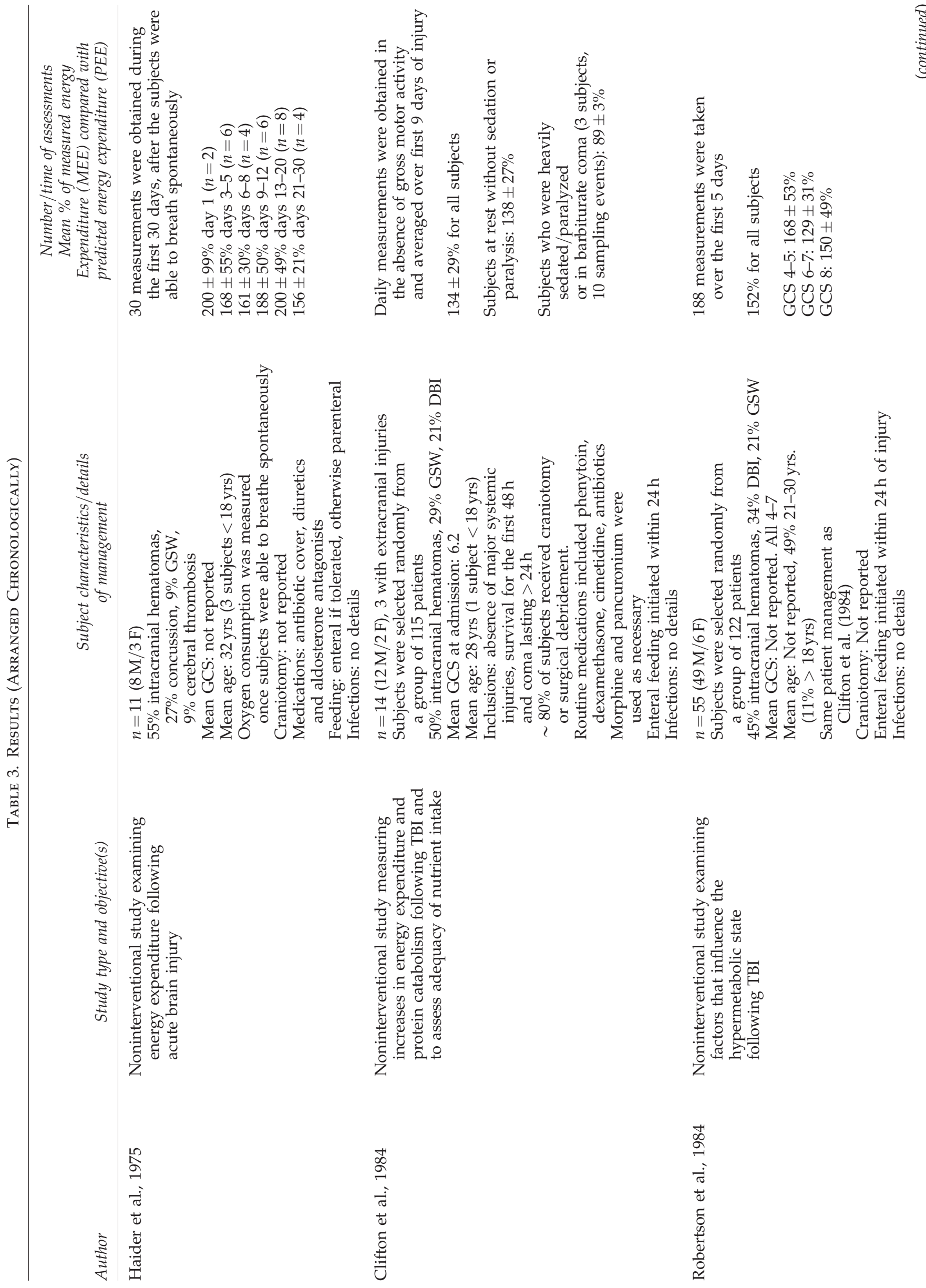




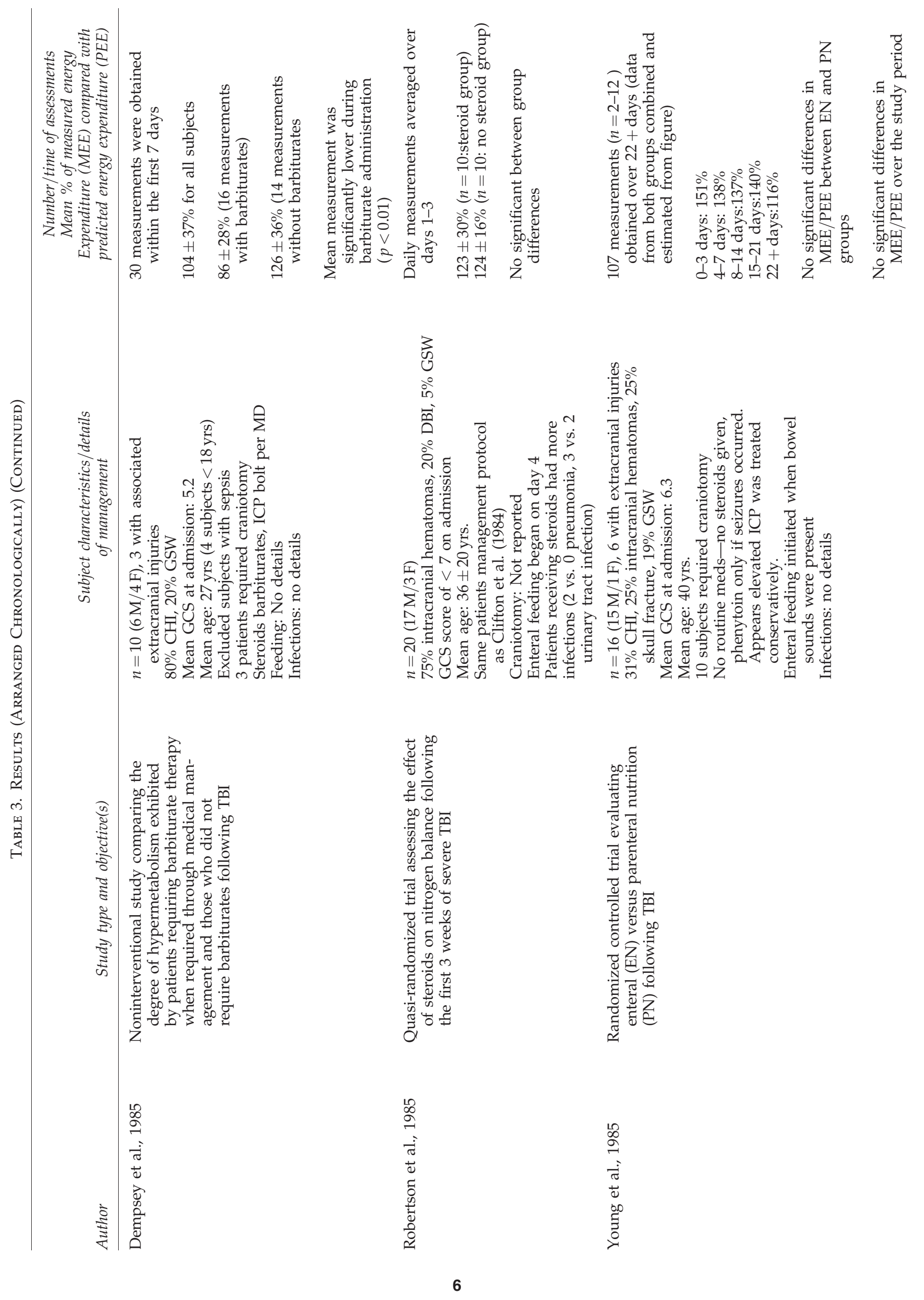



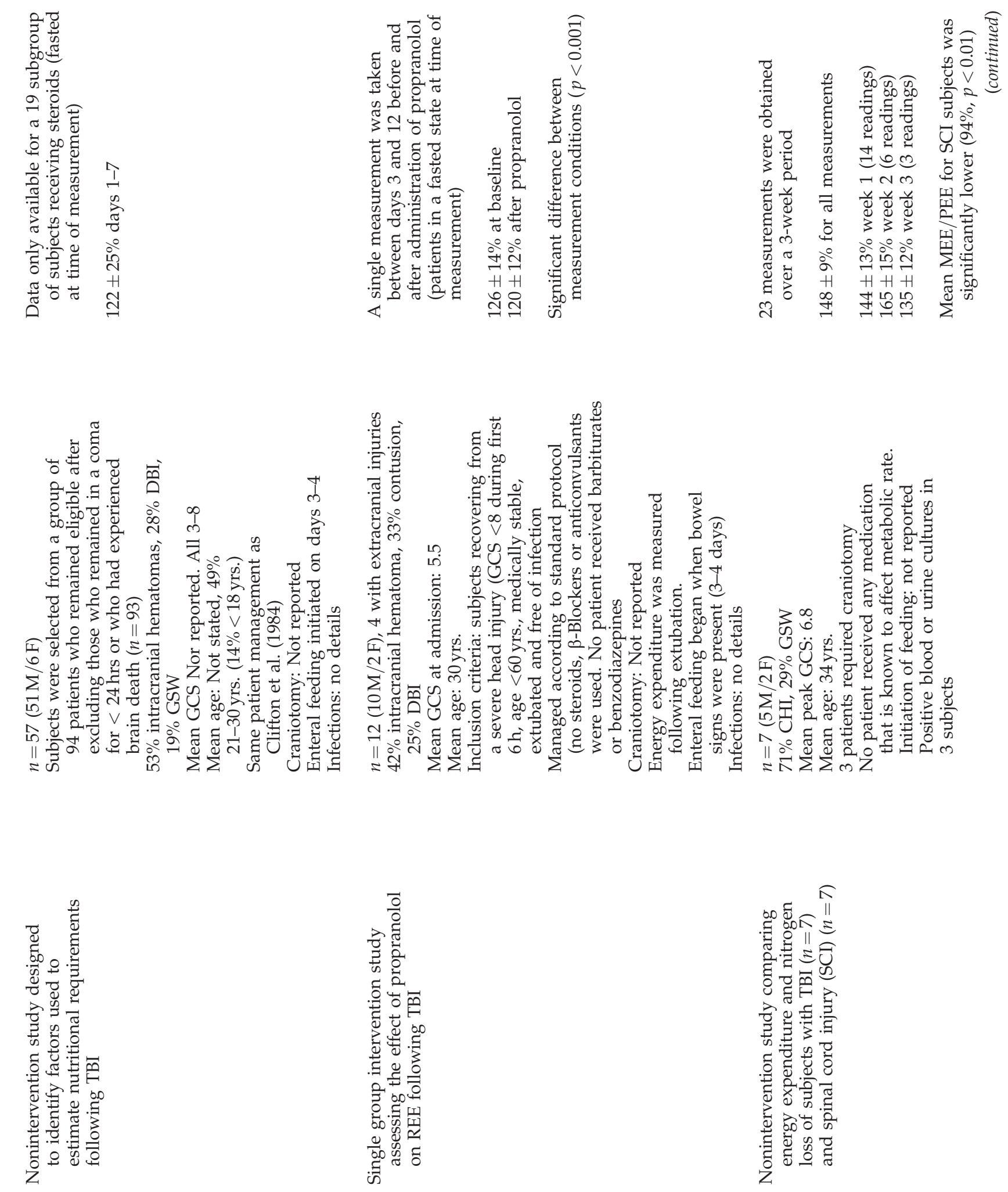

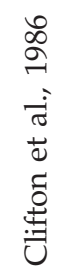

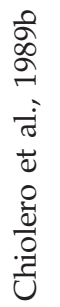

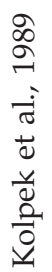




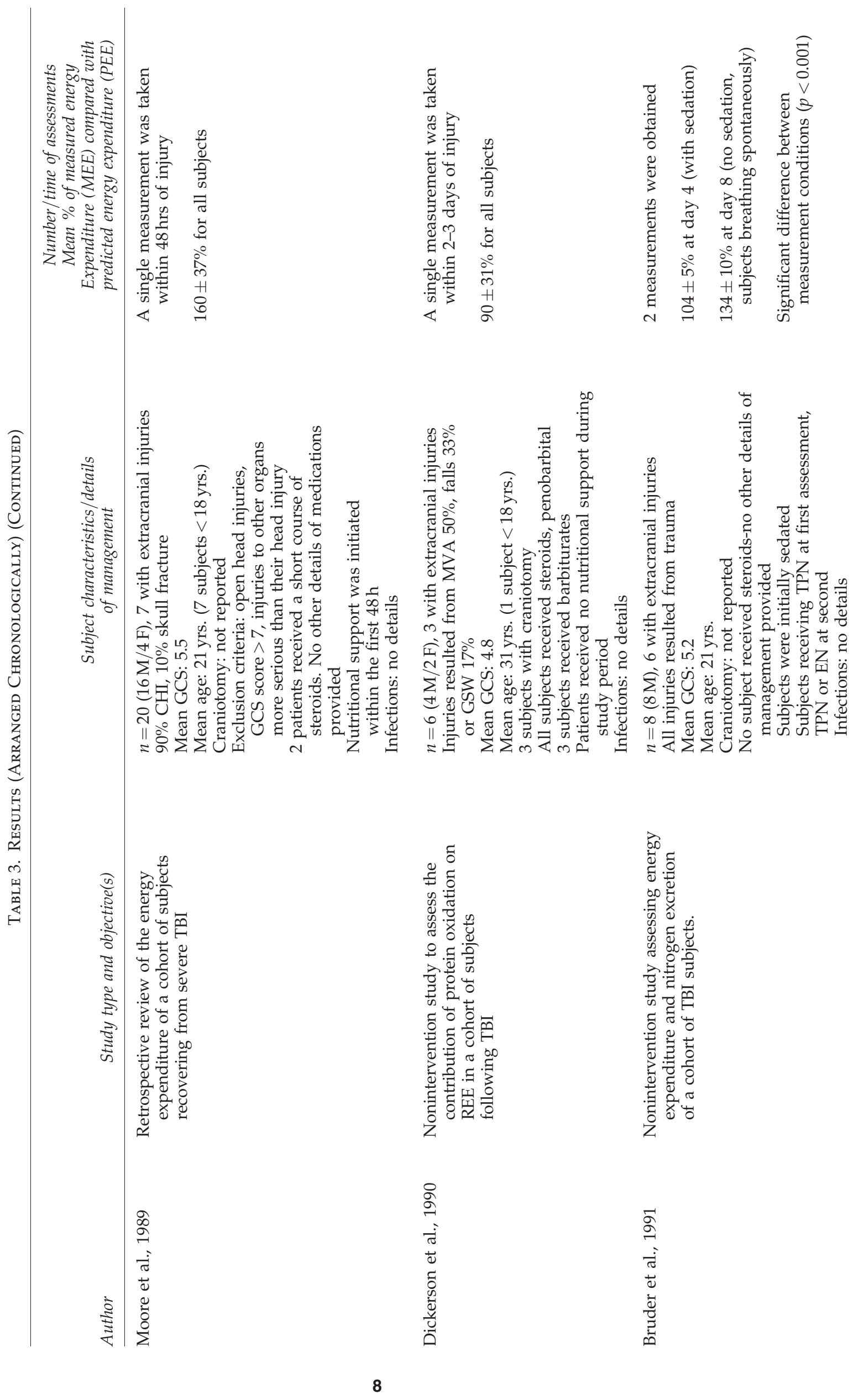



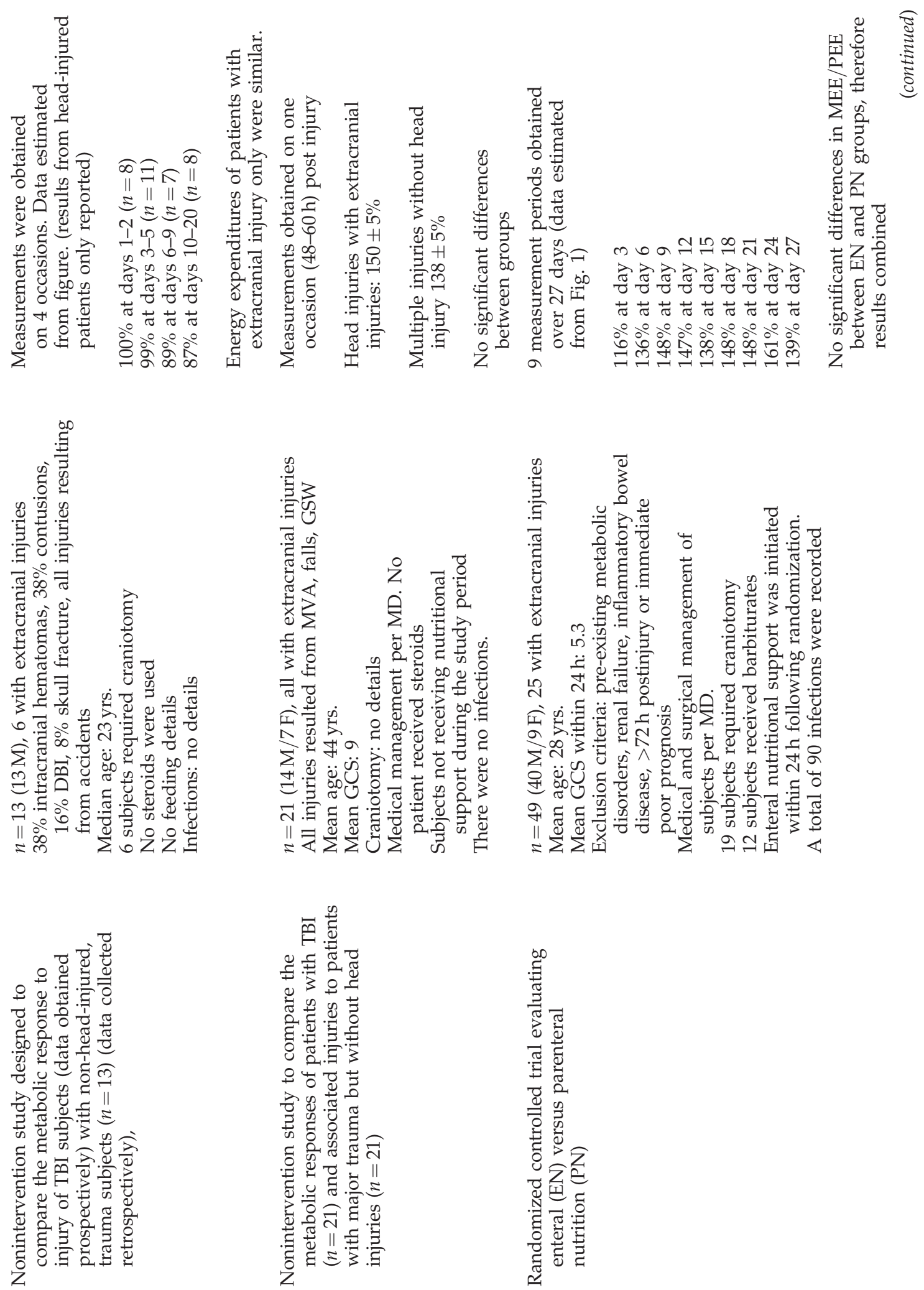

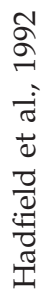

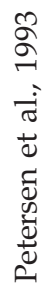

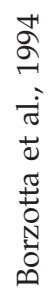



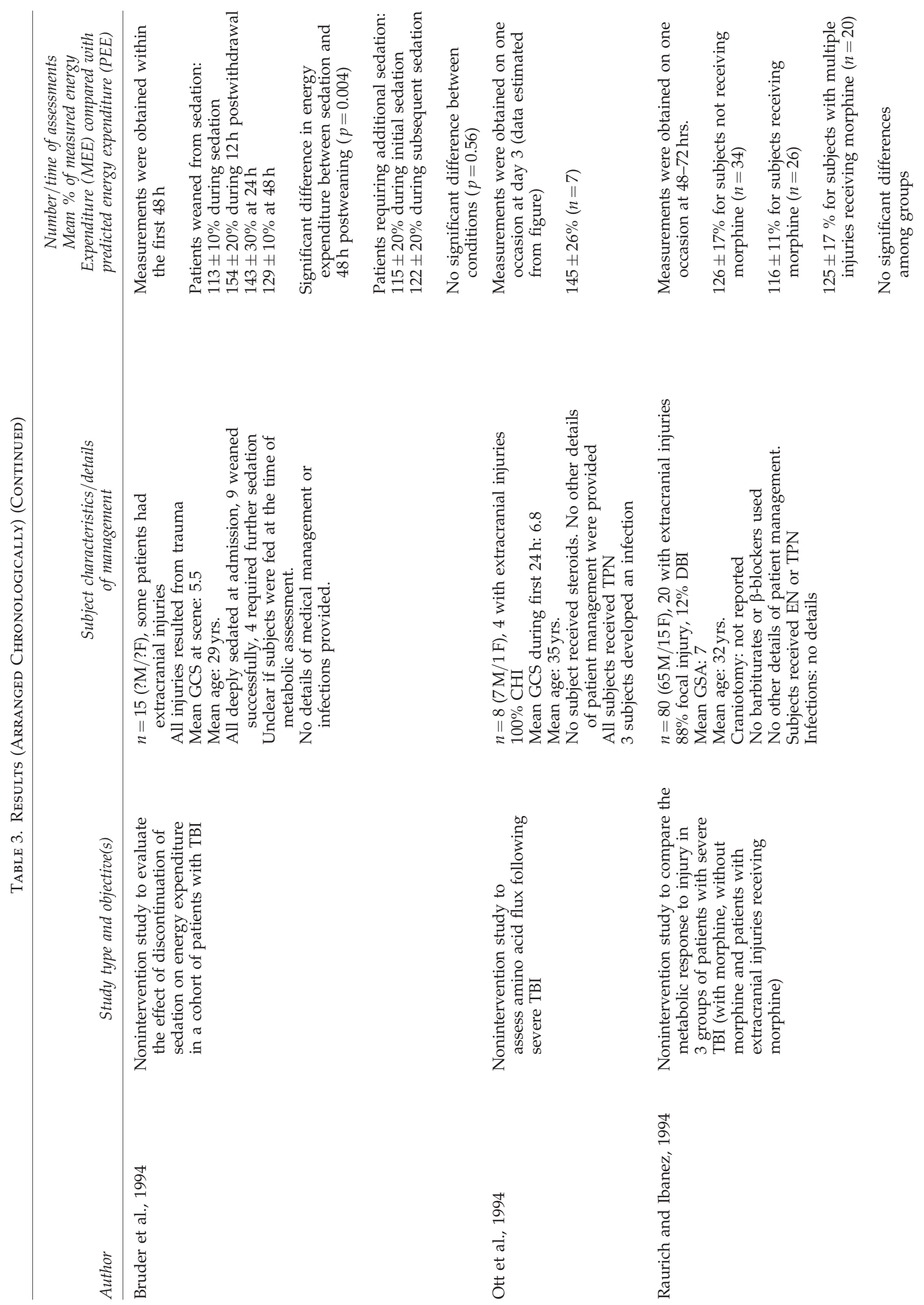

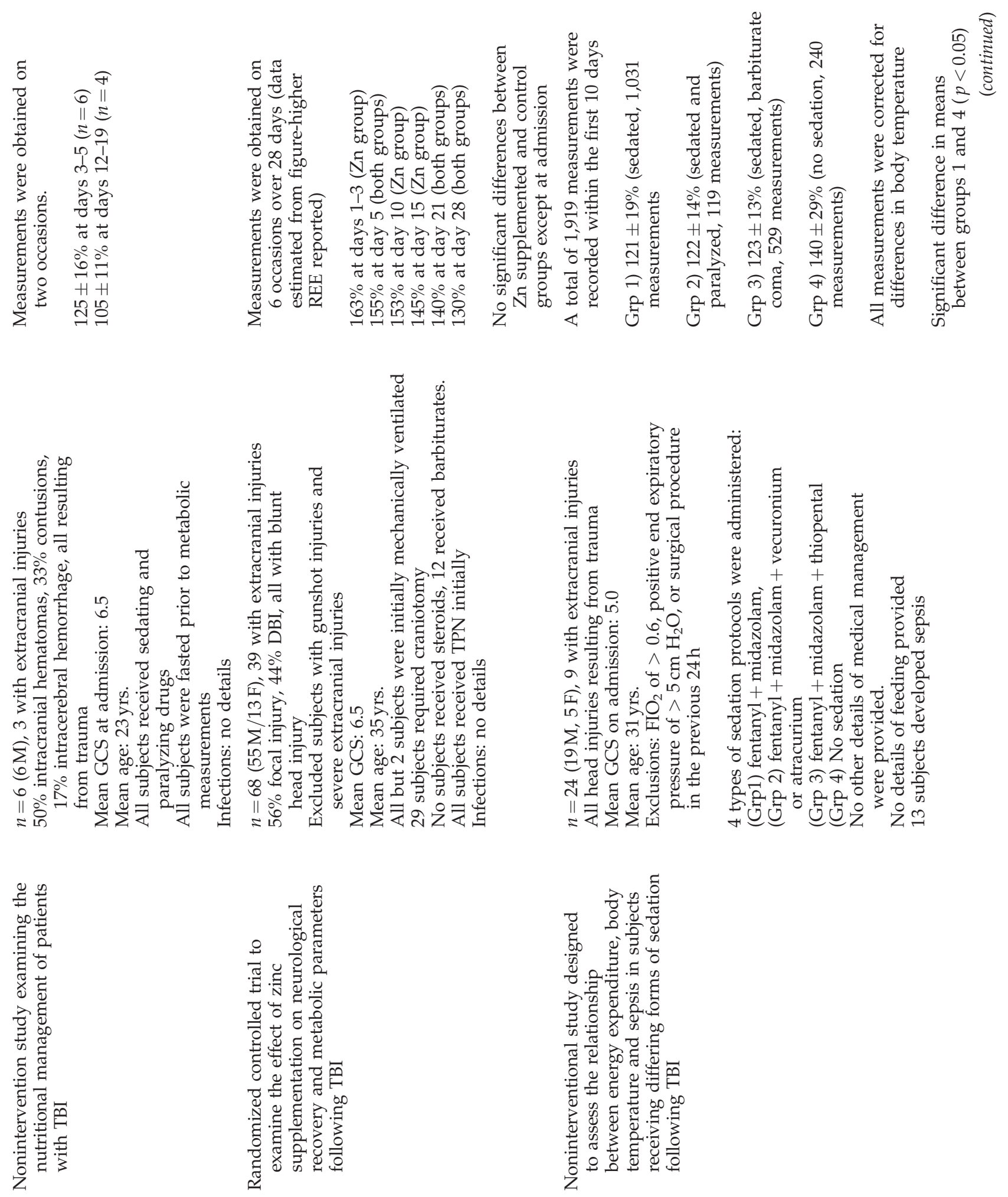

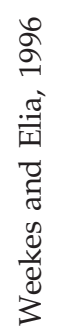

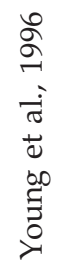

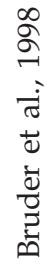




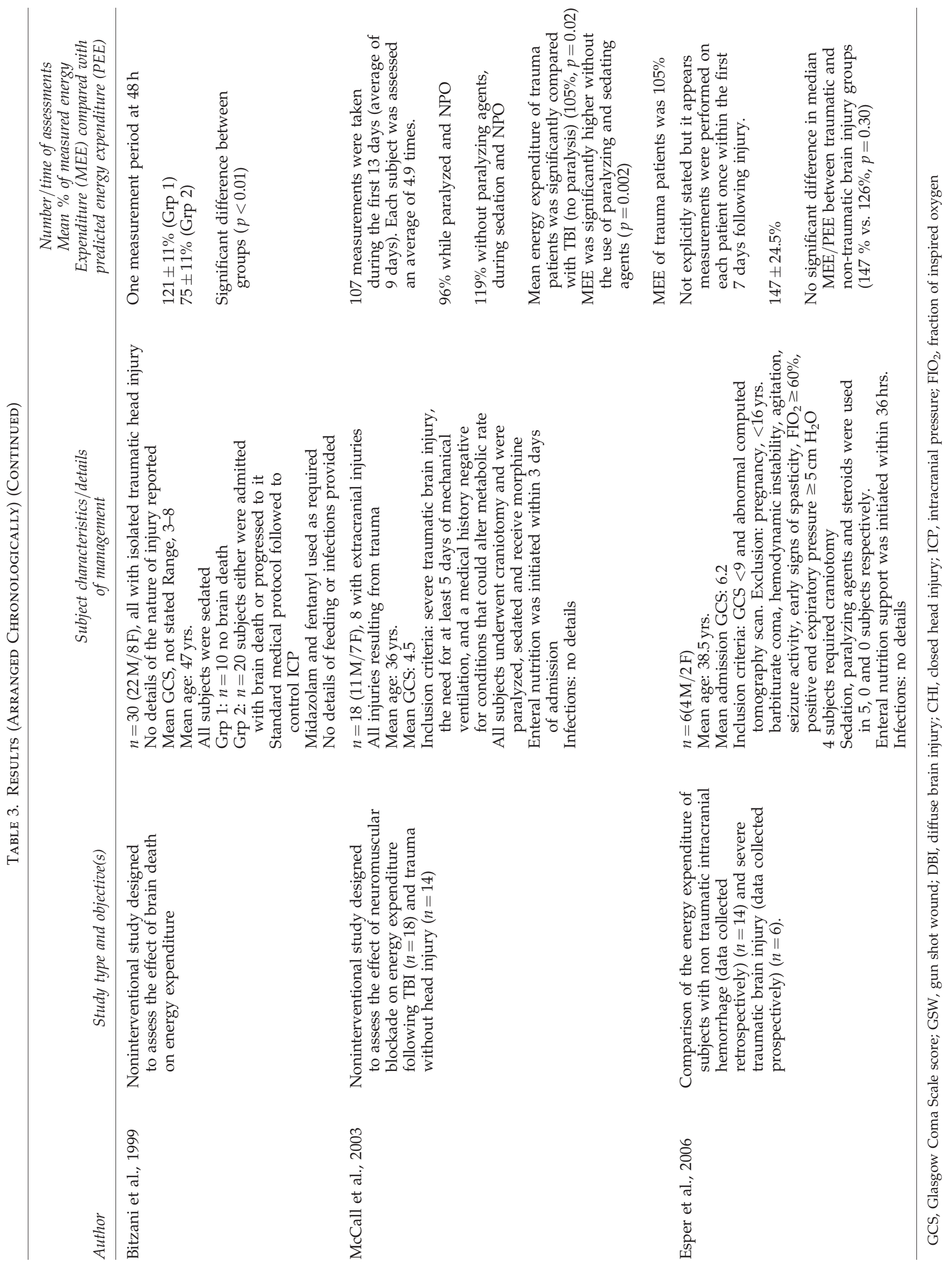


$30 \mathrm{~min}$ to $2 \mathrm{~h}$ (Borzotta et al., 1994; Bruder et al., 1994; Chiolero et al., 1989b; McCall et al., 2003; Robertson et al., 1984, 1985), or were measured continuously over a 24-h period (Bruder et al., 1991, 1998). Weekes and Elia (1996) obtained measurements that were collected over a 24 -h period on one occasion and for less than $30 \mathrm{~min}$ on the second occasion. Metabolic measurements were taken when subjects were both artificially ventilated and breathing spontaneously. In two studies, patients were breathing spontaneously at the time when all metabolic measurements were performed (Chiolero et al., 1989b; Haider et al., 1975). The authors of two studies stated that patients were not receiving neuromuscular blockade at the time of metabolic assessment (Haider et al., 1975; Young et al., 1985), and Chiolero et al. (1989b) stated that measurements were taken during periods when there was no significant muscular activity.

Twelve authors specified measurement of REE (Bitzani et al., 1999; Chiolero et al., 1989b; Clifton et al., 1984; Dempsey et al., 1985; Dickerson et al., 1990; McCall et al., 2003; Moore et al., 1989; Petersen et al., 1993; Raurich and Ibanez, 1994; Robertson et al., 1984, 1985) or basal metabolic rate (Weekes and Elia, 1996), while the remainder simply stated that they had measured "energy expenditure." The authors of most studies conducted metabolic measurements without feeding interruptions (Borzotta et al., 1994; Bruder et al., 1991; Clifton et al., 1984, 1986; Hadfield et al., 1992; Haider et al., 1975; Kolpek et al., 1989; McCall et al., 2003; Moore et al., 1989; Ott et al., 1994; Raurich and Ibanez, 1994; Robertson et al., 1984, 1985; Young et al., 1996), while patients in four trials were fasted prior to assessments (Chiolero et al., 1989b; Dickerson et al., 1990; Petersen et al., 1993; Weekes and Elia, 1996).

The Harris Benedict (HB) equation was used in 18 studies to predict REE. An alternate prediction equation (Elia and Livesey, 1992; Owen, 1988) was also used in two studies (Hadfield et al., 1992; McCall et al., 2003). A nomogram (Boothby et al., 1936) was used in two studies (Clifton et al., 1984; Haider et al., 1975). Finally, the method used to estimate energy expenditure was not stated explicitly in four trials (Borzotta et al., 1994; Clifton et al., 1986; Robertson et al., 1984, 1985).
The number of occasions upon which energy expenditure was measured, as well as the number of subjects represented at each testing interval, varied widely among studies (Table 3). During the first 7 days following injury, mean energy expenditure expressed as a percentage of a predicted value ranged from $75 \%$ in subjects admitted in brain death, (Bitzani et al., 1999) to $200 \%$ (Haider et al., 1975). Both of these results were obtained within the first $48 \mathrm{~h}$ of admission. During the second week post-injury, the mean results ranged from $89 \%$ (Hadfield et al., 1992) to 161\% (Haider et al., 1975), and during the third and forth weeks, mean energy expenditure ranged from $116 \%$ (Young et al., 1985) to $200 \%$ (Haider et al., 1975) of predicted values.

Figure 1 represents the pattern of energy expenditure during the first 30 days following head injury based on data from 15 studies that reported results from measurement/ assessment on specified days, or a narrow range of days, postinjury (Bitzani et al., 1999; Borzotta et al., 1994; Bruder et al., 1991, 1994; Dickerson et al., 1990; Hadfield et al., 1992; Haider et al., 1975; Moore et al., 1989; Ott et al., 1994; Petersen et al., 1993; Raurich and Ibanez, 1994; Robertson et al., 1985; Weekes and Elia, 1996; Young et al., 1985, 1996). Data from nine studies that reported only a single, combined mean value for all metabolic measurements obtained during the study period, lasting 5-13 days, were excluded (Bruder et al., 1998; Chiolero et al., 1989b; Clifton et al., 1984, 1986; Dempsey et al., 1985; Esper et al., 2006; Kolpek et al., 1989; McCall et al., 2003; Robertson et al., 1984).

Subjects receiving paralyzing agents, sedatives, or barbiturate therapy demonstrated significantly lower energy expenditures. The mean REE of sedated patients ranged from $86 \%$ to $121 \%$ of predicted values compared with non-sedated patients, which ranged from $126 \%$ to $140 \%$ (Bruder et al., 1994, 1998; Dempsey et al., 1985). The mean energy expenditures of patients who were paralyzed were also lower $(89-128 \%$ of predicted) compared with samples from subjects who were not (119-159\%) (Bruder et al., 1998; Clifton et al., 1984, 1986; McCall et al., 2003; Robertson et al., 1984). Propranolol administration decreased energy expenditure by 5\% (Chiolero et al., 1989b) and 18\% (Robertson et al., 1984). Morphine was associated with an 8\% (Raurich and Ibanez, 1994) decrease in
FIG. 1. Pattern of energy expenditure during the first 30 days post-injury.

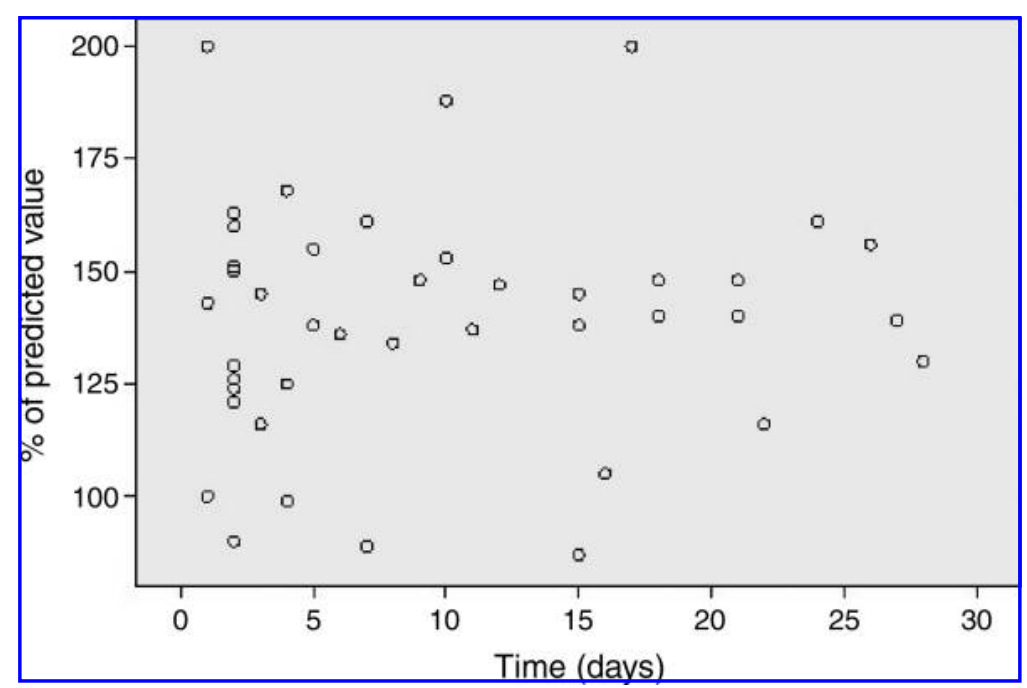


energy expenditure. There were no differences in the mean energy expenditure of patients receiving steroids compared with those who did not (Robertson et al., 1985) or between those receiving enteral or parenteral nutrition (Borzotta et al., 1994; Young et al., 1985).

Six authors examined the relationship between energy expenditure and body temperature. Of the four trials that reported the results for the whole study group, a positive correlation was reported in one study $(r=0.44, p<0.01)$ (Clifton et al., 1984) and no association was reported in three studies (Chiolero et al., 1989b; Hadfield et al., 1992; Robertson et al., 1984). There was an association between temperature and energy expenditures reported for subjects with greater severity of head injury (Robertson et al., 1984), brain death (Bitzani et al., 1999), those receiving sedation, and/or sepsis (Bruder et al., 1998).

The results from four trials indicated that there were no differences in energy expenditures of subjects with isolated head injury compared with those who presented with accompanying extracranial injury (Borzotta et al., 1994; McCall et al., 2003; Raurich and Ibanez, 1994; Young et al., 1985), while the results from two studies comparing subjects with head injury (both with and without associated extracranial injury) and general trauma patients were conflicting. McCall et al. (2003) reported significantly increased mean energy expenditure associated with head injury, while Petersen et al. (1993) did not. The percentages of head-injured subjects suffering from extracranial injuries in the subgroups of these two studies were $44 \%$ (McCall et al., 2003) and 100\% (Petersen et al., 1993). McCall et al. (2003) reported no association between energy expenditure and severity of head injury, while Robertson et al. (1984) reported that subjects with lower GCS had higher energy expenditures.

In the only study to examine the relationship, the mean energy expenditure of patients in the fed state was $9 \%$ higher than patients in the fasted state $(22.3$ vs. $24.6 \mathrm{Kcals} / \mathrm{kg}$, $p=0.002$ ) (McCall et al., 2003). Among the studies that reported details of sepsis or infection, the relationship with energy expenditure was examined in only one (Bruder et al., 1998). The results from this study indicate that MEE was higher than predicted in subjects with sepsis compared with no infection ( $128 \%$ vs. $119 \% ; p<0.001)$.

\section{Discussion}

Based on the results of this review, we can confirm that energy expenditure is increased following moderate to severe acute head injury in most patients, but the results were highly variable. Measurements for most subjects fell outside of the normal range. In subjects who were considered to be hypermetabolic, the mean percentage of MEE/PEE ranged from a low of $116 \%$ at day 3 (Borzotta et al., 1994) to a high value of $200 \%$ (Haider et al., 1975). Energy expenditures of subjects were measured serially (two to nine times) in seven trials over 10-30 days. Subjects in five of these trials were hypermetabolic at all testing occasions (Borzotta et al., 1994; Haider et al., 1975; Kolpek et al., 1989; Young et al., 1985, 1996). In only one trial were energy expenditures consistently at, or below, predicted values (Hadfield et al., 1992). Bitzani et al. (1999) reported the lowest energy expenditures following brain death, a finding which was attributed to decrease in oxygen consumption by the brain, which may be anticipated since the brain is known to consume $20 \%$ of total caloric requirement (Pevsner et al., 1971).

We are aware of only one previous systematic review of hypermetabolism following TBI that incorporated the results from 14 trials, published from 1993 through 2003 (Krakau et al., 2006). These authors reported similar, although less variable results compared with the present study, with deviations in MEE/PEE of $96-160 \%$. The authors attributed most of the inconsistency of results to variability in measurement procedures. Due to differences in eligibility criteria, the present study included only eight of the same studies (Borzotta et al., 1994; Bruder et al., 1994, 1998; McCall et al., 2003; Ott et al., 1994; Raurich and Ibanez, 1994; Weekes and Elia, 1996; Young et al., 1996). Since we did not impose publication date restrictions, and used patient level data or estimates from figures when summary statistics were not provided, we were able to summarize data from an additional 16 studies. We explored additional sources of heterogeneity among studies including medical management, characteristics of subjects and/or differences associated with timing, and the specifics of measurement technique.

It is difficult to define precisely the effect of medical management on energy expenditure following acute head injury since multiple interventions are commonly used. Treatments, which individually may be expected to either raise or lower energy expenditure, are often provided in combination, rendering the individual contribution from injury difficult to isolate. Patients' neurological status may change frequently and rapidly, necessitating changes in medical management; therefore, the requirement for, and effects of, medications may also be short-lived. For example, patients may require sedation for only short periods of time, during which their metabolic rate may be depressed, but may rise dramatically during withdrawal. The clinical implications of these short-term fluctuations in metabolic rate remain unclear. Nevertheless, based on the results from this review we estimated that sedatives or barbiturates reduced metabolic rate by approximately $13-32 \%$ and paralyzing agents decreased metabolic rate from $12 \%$ to $28 \%$. While the effect of morphine appeared to be more modest, independently decreasing energy expenditure by only 8\% (Raurich and Ibanez, 1994), McCall et al. (2003) reported that $16 \%$ of the variability in MEE change between the paralyzed and non-paralyzed states could be attributed to morphine, suggesting that it is a more potent mediator. Similarly, the clinical significance of the $5 \%$ reduction in energy expenditure following propranolol administration reported in one study (Chiolero et al., 1989b) is likely minimal, although Robertson et al. (1984) reported a more substantial $18 \%$ decline in a subgroup of six patients. Since $10 \%$ of REE is attributed to heart function and propranolol reduces energy expenditure by decreasing the heart rate (Chiolero et al., 1989b), some reduction in energy expenditure can be expected. Based on the results from only a single study (Robertson et al., 1984), we found no evidence that steroids, which were hypothesized to raise metabolic rate by augmenting the stress response, had the purported effect. It is worth noting that the use of steroids post-TBI is now contraindicated (2007a).

Although the route of feeding (enteral versus parenteral), type (continuous versus intermittent), nutrient composition (fat, protein, and carbohydrate), and caloric load are known to influence energy expenditure (Carlson et al., 1994; Forsberg 
et al., 1994; Heymsfield et al., 1987), feeding protocols did not appear to be a major contributor to the variability observed in REE. There were no differences in the energy expenditures reported in studies that compared enteral with parenteral feeding (Borzotta et al., 1994; Young et al., 1985), a finding that has been reported previously in a small sample of healthy individuals (Vernet et al., 1986). The difference in energy expenditure between patients in the fed versus unfed state was attributed to a $10 \%$ thermogenic response to feeding in a single study where the comparison was possible (McCall et al., 2003).

Controlled mechanical ventilation reduces the metabolic cost of spontaneous breathing, which is estimated to be about $4 \%$ in healthy volunteers (Lewis et al., 1988), and up to $25 \%$ during critical illness (Bursztein et al., 1978) and weaning (Lewis et al., 1988). While mode of breathing could have contributed to some of the variability in energy expenditure, insufficient detail was provided in the majority of studies to enable further examination as it was impossible to establish whether subjects were mechanically ventilated or breathing spontaneously during measurements. Similarly, it was not possible to assess whether other manoeuvres common to the care of patients in an intensive care setting, including turning, physiotherapy or suctioning, also led to increased energy expenditure and contributed significantly to the variability among studies, particularly during the first week when interventions may be most intensive.

Differences in injury severity may have accounted for some of the variability in REE across studies. There was conflicting evidence of a relationship between severity of injury and metabolic rate. In one study, patients with GCS scores of 4-5, who exhibited posturing responses to pain, but who were not assessed during periods of posturing, had higher REE compared with patients with GCS scores of 6-7 (Robertson et al., 1984). Surprisingly, the energy expenditures of patients with GCS scores of 8 were intermediate to the other two groups, although patients were described as being restless during measurement. The same authors also noted a positive correlation between oxygen consumption and serum catecholamines. In contrast, McCall et al. (2003) and Clifton et al. (1984) both reported weak, nonsignificant correlations between GCS scores and energy expenditure.

Based on the subgroup results from three studies, the addition of extracranial injury does not appear to increase energy expenditure when compared with isolated head injury (Borzotta et al., 1994; Raurich and Ibanez, 1994; Young et al., 1985). This finding might suggest a systemic effect of the acute phase response, a hypothesis supported by the findings from Petersen et al. (1993), who reported no significant differences in the energy expenditures of patients with head and multiple injuries compared to those with multiple injuries, but no brain injury. However, Haider et al. (1975) speculated that "vegetative dysregulation", an additional factor present in cerebral injury, could account for energy expenditures far in excess of what would be expected following common trauma.

The contribution that increased temperature makes to energy expenditure is unclear based on the results of this review. Bruder et al. (1998) suggested that the increased energy expenditure found in their two earlier publications could be explained entirely on the basis of raised body temperature in sedated patients, using Du Bois's estimate (1954) that there is a $13 \%$ increase in metabolic rate per degree Celsius. However, Clifton et al. (1984) reported elevations in energy expenditure far exceeding that which could be explained on the basis of increased temperature.

The lengths of time that metabolic measurements were taken and the stability of the measurements may also have contributed to the variability since shorter periods of time (i.e., less than $2 \mathrm{~h}$ ) may not have been representative of an entire 24-h period. For example, discarded measurements indicated that energy expenditure increased from $30 \%$ above predicted values to $200 \%$ during periods of posturing (Chiolero et al., $1989 b)$. Similarly, the energy expenditure of one patient fluctuated by more than $25 \%$ during a $24-\mathrm{h}$ period in one study which was assumed to be related to body temperature fluctuations (Weekes and Elia, 1996). Metabolic measurements lasting a full 24-h period were performed in only two trials (Bruder et al., 1991, 1998).

We chose to present our energy expenditure findings in terms of a percentage of a predicted value. While this manoeuvre enabled comparisons across studies, its use may also have introduced a source of variability and error. The HarrisBenedict equation, the most frequently used prediction equation, was developed almost 100 years ago and relied on data from only 239 healthy men and women (Harris and Benedict, 1919). The individual variability in energy expenditures in this sample was substantial. For example, two female subjects weighing 106 and 176 pounds, respectively, each had a basal metabolism of 1,475 Kcals. Furthermore, the use of the $\mathrm{HB}$ equation to estimate energy requirements in the malnourished state, which is common following TBI, has also been questioned since the assumption of a normal body composition is violated. Malnutrition results in a loss of body cell mass and fat, while the extracellular mass expands (Roza and Shizgal, 1984).

While there was no discernable pattern of energy expenditure, the results from this study indicated that hypermetabolism persists for 30 days, although attrition of subjects in almost all studies raises doubts about the validity of this finding. Only seven trials measured the energy expenditure beyond 10 days (Borzotta et al., 1994; Hadfield et al., 1992; Haider et al., 1975; Kolpek et al., 1989; McCall et al., 2003; Young et al., 1985, 1996). Furthermore, the possibility exists that subjects with more severe injuries were over represented in trials with a longer observation period, as subjects with relatively milder injury may have been lost following transfer to other services or discharge, or alternatively, patients with the most severe injury may have died.

Several limitations of this review should be noted. We included only studies written in the English language and, therefore, may have missed relevant data published in nonEnglish language journals. We relied on information that was supplied in the written report only where detail was frequently lacking. Sample sizes in virtually all of the included studies were small, often resulting in a lack of precision of the estimate of energy expenditure. In studies in which group comparisons were reported these small sample sizes with insufficient power may have increased the likelihood of a type II statistical error (claiming no difference between groups when one may have existed). We did not include an assessment of the methodological quality of the individual studies, as is customary, since this review included only three RCTs. The merit of assessing the quality of observational trials, which intrinsically lack rigor, has been questioned. Bias may have been introduced by including studies published over 30 
years ago. Gains in knowledge and technological advances might mean that intracranial pressure, which has been shown to correlate with metabolic rate, is managed more effectively today than in previous years. Consequently, we might reasonably have expected to see a blunting of the hypermetabolic response reported in more recent studies compared with older ones. However, with the exception of the earliest study where the highest level was reported, more recently published studies reported increases in energy expenditure that were in excess of $150 \%$ of predicted values.

\section{Conclusion}

Following a review of 24 studies assessing energy expenditure following TBI, we found that metabolic rate is highly variable. The lowest value (75\% of predicted) was reported in patients admitted with a diagnosis of brain death. Overall, in the remaining studies, metabolic rates ranged from $87 \%$ to $200 \%$ of predicted values at some point during the first 30 days post-injury. We estimated that paralyzing agents, sedatives, or barbiturates reduced metabolic rate by approximately $12-36 \%$. Morphine and propranolol decreased energy expenditure by $8 \%$ and $5 \%$, respectively. Factors that do not appear to augment the hypermetabolic response included the administration of steroids and the route of feeding (enteral vs. parenteral). It is unclear if increased severity of injury, the presence of extracranial injury, or elevated temperature contributes significantly to the hypermetabolic state. While the results of this study have implications for guiding clinical practice, particularly when indirect calorimetry is unavailable, they should not be used to estimate energy requirements for individual patients.

\section{Author Disclosure Statement}

No competing financial interests exist.

\section{Acknowledgments}

This project was funded in part by a grant from the Ontario Neurotrauma Foundation.

\section{References}

Brain Trauma Foundation; American Association of Neurological Surgeons; Joint Section on Neurotrauma and Critical Care. (2000). Nutrition. J. Neurotrauma 17, 539-547.

Brain Trauma Foundation; American Association of Neurological Surgeons; Congress of Neurological Surgeons; Joint Section on Neurotrauma and Critical Care. (2007a). Guidelines for the management of severe traumatic brain injury. XV. Steroids. J. Neurotrauma 24, S91-S95.

Brain Trauma Foundation; American Association of Neurological Surgeons; Congress of Neurological Surgeons; Joint Section on Neurotrauma and Critical Care. (2007b). Guidelines for the management of severe traumatic brain injury. XII. Nutrition. J. Neurotrauma 24, S77-S82.

Baker, S.P., O’Neill, B., Haddon, W., Jr., and Long, W.B. (1974). The injury severity score: a method for describing patients with multiple injuries and evaluating emergency care. J. Trauma 14, 187-196.

Bitzani, M., Matamis, D., Nalbandi, V., Vakalos, A., Karasakalides, A., and Riggos, D. (1999). Resting energy expenditure in brain death. Intensive Care Med. 25, 970-976.
Boothby, W.M., Berkson, J., and Dunn, H.L. (1936). Studies of the energy metabolism of normal individuals: a standard for basal metabolism with a monogram for clinical application. Am. J. Physiol. 116, 468.

Borzotta, A.P., Pennings, J., Papasadero, B., Paxton, J., Mardesic, S., Borzotta, R., Parrott, A., and Bledsoe, F. (1994). Enteral versus parenteral nutrition after severe closed head injury. J. Trauma 37, 459-468.

Bruder, N., Dumont, J.C., and Francois, G. (1991). Evolution of energy expenditure and nitrogen excretion in severe head-injured patients. Crit. Care Med. 19, 43-48.

Bruder, N., Lassegue, D., Pelissier, D., Graziani, N., and Francois, G. (1994). Energy expenditure and withdrawal of sedation in severe head-injured patients. Crit. Care Med. 22, 1114-1119.

Bruder, N., Raynal, M., Pellissier, D., Courtinat, C., and Francois, G. (1998). Influence of body temperature, with or without sedation, on energy expenditure in severe head-injured patients. Crit. Care Med. 26, 568-572.

Bursztein, S.,Taitelman, U., De Myttenaere, S., Michelson, M., Dahan, E., Gepstein, R., Edelman, D., and Melamed, Y. (1978). Reduced oxygen consumption in catabolic states with mechanical ventilation. Crit. Care Med. 6, 162-164.

Carlson, G.L., Gray, P., Arnold, J., Little, R.A., and Irving, M.H. (1994). Thermogenic, hormonal, and metabolic effects of a TPN mixture. Influence of glucose and amino acids. Am. J. Physiol 266, E845-E851.

Chiolero, R., Schutz, Y., Lemarchand, T., Felber, J.P., de Tribolet, N., Freeman, J., and Jequier, E. (1989a). Hormonal and metabolic changes following severe head injury or noncranial injury. IPEN J. Parenter. Enteral Nutr. 13, 5-12.

Chiolero, R.L., Breitenstein, E., Thorin, D., Christin, L., de Tribolet, N., Freeman, J., Jequier, E., and Schutz, Y. (1989b). Effects of propranolol on resting metabolic rate after severe head injury. Crit. Care Med. 17, 328-334.

Clifton, G.L., Robertson, C.S., and Choi, S.C. (1986). Assessment of nutritional requirements of head-injured patients. J. Neurosurg. 64, 895-901.

Clifton, G.L., Robertson, C.S., Grossman, R.G., Hodge, S., Foltz, R., and Garza, C. (1984). The metabolic response to severe head injury. J. Neurosurg. 60, 687-696.

Dempsey, D.T., Guenter, P., Mullen, J.L., Fairman, R., Crosby, L.O., Spielman, G., and Gennarelli, T. (1985). Energy expenditure in acute trauma to the head with and without barbiturate therapy. Surg. Gynecol. Obstet. 160, 128-134.

Dickerson, R.N., Guenter, P.A., Gennarelli, T.A., Dempsey, D.T., and Mullen, J.L. (1990). Increased contribution of protein oxidation to energy expenditure in head-injured patients. $\underline{\text {. Am. }}$. Coll. Nutr. 9, 86-88.

Elia, M., and Livesey, G. (1992). Energy expenditure and fuel selection in biological systems: the theory and practice of calculations based on indirect calorimetry and tracer methods. World Rev. Nutr. Diet 70, 68-131.

Elwyn, D.H. (1980). Nutritional requirements of adult surgical patients. Crit. Care Med. 8, 9-20.

Esper, D.H., Coplin, W.M., and Carhuapoma, J.R. (2006). Energy expenditure in patients with nontraumatic intracranial hemorrhage. JPEN J. Parenter. Enteral Nutr. 30, 71-75.

Forsberg, E., Soop, M., Lepapea, A., and Thorne, A. (1994). Metabolic and thermogenic response to continuous and cyclic total parenteral nutrition in traumatised and infected patients. Clin. Nutr. 13, 291-301.

Hadfield, J.M., Little, R.A., and Jones, R.A. (1992). Measured energy expenditure and plasma substrate and hormonal changes after severe head injury. Injury 23, 177-182. 
Haider, W., Lackner, F., Schlick, W., Benzer, H., Gerstenbrand, F., Irsingler, K., Korn, A., Frystof, G., and Mayrhofer, O. (1975). Metabolic changes in the course of severe acute brain damage. Eur. J. Intensive Care Med. 1, 19-26.

Harris, J.A., and Benedict, F.G. (1919). A Biometric Study of Basal Metabolism in Man. Carnegie Institute of Washington: Washington, D.C.

Heymsfield, S.B., Hill, J.O., Evert, M., Casper, K., and DiGirolamo, M. (1987). Energy expenditure during continuous intragastric infusion of fuel. Am. J. Clin. Nutr. 45, 526-533.

Kolpek, J.H., Ott, L.G., Record, K.E., Rapp, R.P., Dempsey, R., Tibbs, P., and Young, B. (1989). Comparison of urinary urea nitrogen excretion and measured energy expenditure in spinal cord injury and nonsteroid-treated severe head trauma patients. JPEN J. Parenter. Enteral Nutr. 13, 277-280.

Krakau, K., Omne-Ponten, M., Karlsson, T., and Borg, J. (2006). Metabolism and nutrition in patients with moderate and severe traumatic brain injury: a systematic review. Brain Inj. 20, 345-367.

Lewis, W.D., Chwals, W., Benotti, P.N., Lakshman, K., O'Donnell, C., Blackburn, G.L., and Bistrian, B.R. (1988). Bedside assessment of the work of breathing. Crit. Care Med. 16, 117122.

Loan, T. (1999). Metabolic/nutritional alterations of traumatic brain injury. Nutrition 15, 809-812.

Long, C.L., Schaffel, N., Geiger, J.W., Schiller, W.R., and Blakemore, W.S. (1979). Metabolic response to injury and illness: estimation of energy and protein needs from indirect calorimetry and nitrogen balance. JPEN J. Parenter. Enteral Nutr. 3, 452-456.

McCall, M., Jeejeebhoy, K., Pencharz, P., and Moulton, R. (2003). Effect of neuromuscular blockade on energy expenditure in patients with severe head injury. IPEN J. Parenter. Enteral Nutr. 27, 27-35.

Moore, R., Najarian, M.P., and Konvolinka, C.W. (1989). Measured energy expenditure in severe head trauma. I. Trauma $29,1633-1636$.

Ott, L., McClain, C., and Young, B. (1989). Nutrition and severe brain injury. Nutrition 5, 75-79.

Ott, M., Schmidt, J., Young, B., Ott, L., Kryscio, R., and McClain, C. (1994). Nutritional and metabolic variables correlate with amino acid forearm flux in patients with severe head injury. Crit. Care Med. 22, 393-398.

Owen, O.E. (1988). Resting metabolic requirements of men and women. Mayo Clin. Proc. 63, 503-510.

Pepe, J.L., and Barba, C.A. (1999). The metabolic response to acute traumatic brain injury and implications for nutritional support. J. Head Trauma Rehabil. 14, 462-474.

Petersen, S.R., Jeevanandam, M., and Harrington, T. (1993). Is the metabolic response to injury different with or without severe head injury? Significance of plasma glutamine levels. J. Trauma 34, 653-660.

Pevsner, P.H., Bhushan, C., Ottesen, O.E., and Walker, A.E. (1971). Cerebral blood flow and oxygen consumption. An online technique. Johns Hopkins Med. J. 128, 134-140.

Rapp, R.P., Young, B., Twyman, D., Bivins, B.A., Haack, D., Tibbs, P.A., and Bean, J.R. (1983). The favorable effect of early parenteral feeding on survival in head-injured patients. J. Neurosurg. 58, 906-912.

Raurich, J.M., and Ibanez, J. (1994). Metabolic rate in severe head trauma. JPEN J. Parenter. Enteral Nutr. 18, 521-524.

Roberts, P.R. (1995). Nutrition in the head-injured patient. $\underline{\mathrm{New}}$ Horiz. 3, 506-517.

Robertson, C.S., Clifton, G.L., and Goodman, J.C. (1985). Steroid administration and nitrogen excretion in the head-injured patient. J. Neurosurg. 63, 714-718.

Robertson, C.S., Clifton, G.L., and Grossman, R.G. (1984). Oxygen utilization and cardiovascular function in head-injured patients. Neurosurgery 15, 307-314.

Roza, A.M., and Shizgal, H.M. (1984). The Harris Benedict equation reevaluated: resting energy requirements and the body cell mass. Am. J. Clin. Nutr. 40, 168-182.

Vernet, O., Christin, L., Schutz, Y., Danforth, E., Jr., and Jequier, E. (1986). Enteral versus parenteral nutrition: comparison of energy metabolism in healthy subjects. Am. J. Physiol. 250, E47-E54.

Villet, S., Chiolero, R.L., Bollmann, M.D., Revelly, J.P., Cayeux, R.N.M., Delarue, J., and Berger, M.M. (2005). Negative impact of hypocaloric feeding and energy balance on clinical outcome in ICU patients. Clin. Nutr. 24, 502-509.

Weekes, E., and Elia, M. (1996). Observations on the patterns of 24-hour energy expenditure changes in body composition and gastric emptying in head-injured patients receiving nasogastric tube feeding. IPEN J. Parenter. Enteral Nutr. 20, 31-37.

Wilson, R.F., and Tyburski, J.G. (1998). Metabolic responses and nutritional therapy in patients with severe head injuries. J. Head Trauma Rehabil. 13, 11-27.

Yanagawa, T., Bunn, F., Roberts, I., Wentz, R., and Pierro, A. (2002). Nutritional support for head-injured patients. Cochrane Database Syst. Rev. CD001530.

Young, A.B., Ott, L.G., Beard, D., Dempsey, R.J., Tibbs, P.A., and McClain, C.J. (1988). The acute-phase response of the braininjured patient. J. Neurosurg. 69, 375-380.

Young, B., Ott, L., Kasarskis, E., Rapp, R., Moles, K., Dempsey, R.J., Tibbs, P.A., Kryscio, R., and McClain, C. (1996). Zinc supplementation is associated with improved neurologic recovery rate and visceral protein levels of patients with severe closed head injury. J. Neurotrauma 13, 25-34.

Young, B., Ott, L., Norton, J., Tibbs, P., Rapp, R., McClain, C., and Dempsey, R. (1985). Metabolic and nutritional sequelae in the non-steroid treated head injury patient. Neurosurgery 17, 784-791.

Young, B., Ott, L., Yingling, B., and McClain, C. (1992). Nutrition and brain injury. J. Neurotrauma 9, S375-S383.

Address reprint requests to: Norine Foley, M.Sc. Aging, Rehabilitation \& Geriatric Care Program Lawson Health Research Institute Parkwood Hospital, Room B-3019b 801 Commissioner's Road East London, ON, N6C 5J1, Canada

E-mail: norine.foley@sjhc.london.on.ca 
